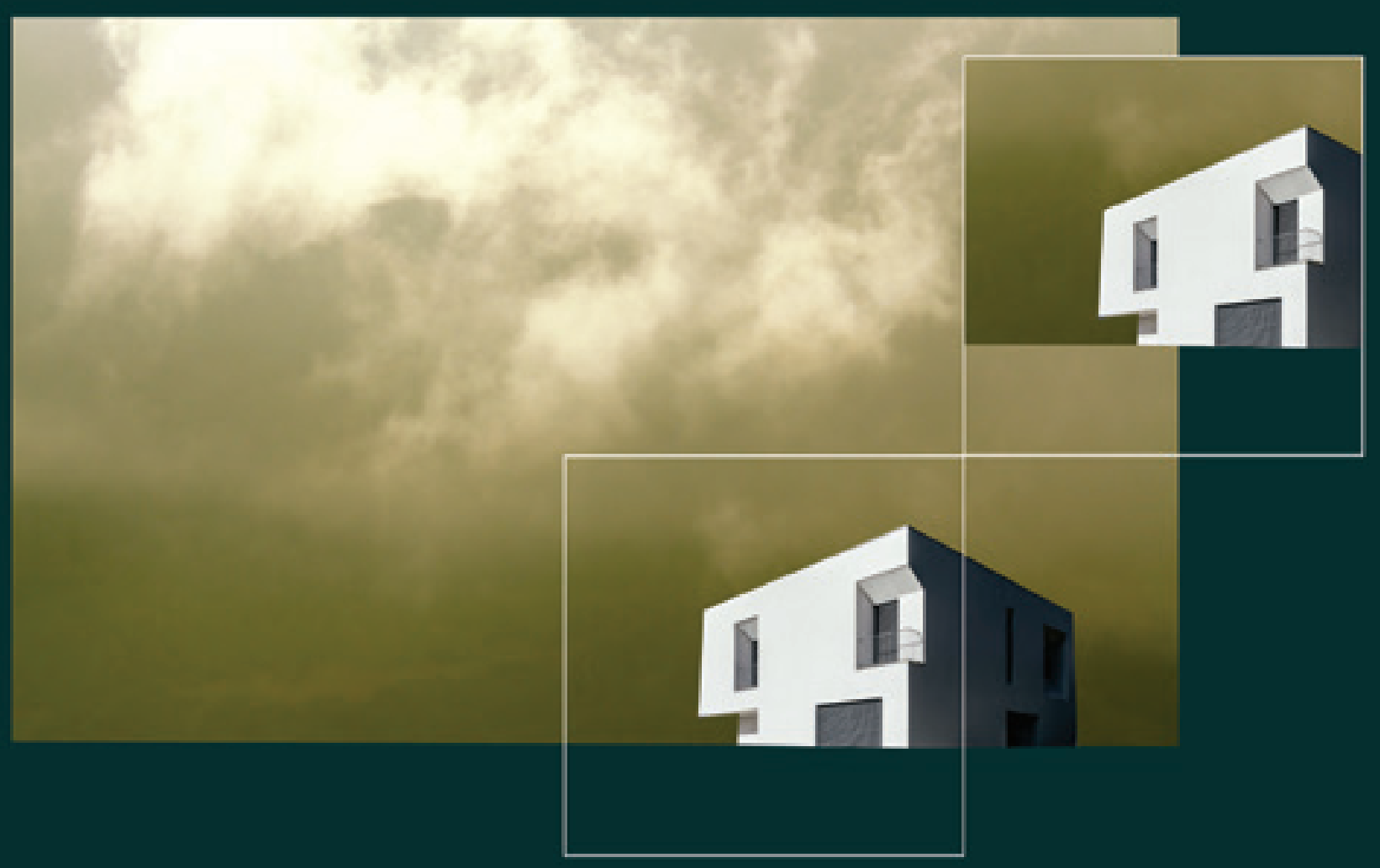




\section{O Valor do Lazer no Jogo da Essência e Aparência das Relações Sociais Capitalistas}

The Value of Leisure in the Game of Essence and Appearance of Capitalist Social Relations

Shaiane Vargas da Silveira ${ }^{1}$

1 Doutora em Políticas Públicas (Universidade Federal do Maranhão, Brasil/ Instituto de Estudos de Ocio, Universidad de Deusto, Bilbao, Espanha). Docente da Universidade Federal do Piauí, Parnaíba, Piauí, Brasil. E-mail: shaiane@pq.cnpq.br 


\title{
Resumo
}

O artigo apresenta uma reflexão sobre o lazer, seus significados e contradições na sociedade capitalista, enfatizando o jogo da essência e aparência como metáfora explicativa. Trata do valor de uso e valor de troca como características fundantes da diferenciação da essência e aparência do lazer. Contempla o leitor como uma perspectiva vinculada aos conceitos de experiência valiosa e lazer humanista. 0 objetivo da pesquisa é compreender como é possível superar as contradições do lazer e romper a lógica do capital nas intervenções promovidas pelo Estado. A construção dessa análise crítica contemplou o referencial teórico que apresenta as contradições do lazer estimuladas pelas relações sociais capitalistas.

Palavras-chave: Lazer. Trabalho. Capitalismo.

\begin{abstract}
The article presents a study on leisure, its meanings and contradictions in the capitalist society, emphasizing the game of essence and appearance as an explanatory metaphor. It considers use value and exchange value as founding features of differentiation of the essence and appearance in leisure. It offers the reader a perspective linked to the concepts of valuable experience and humanist leisure in order to understand how it is possible to overcome the contradictions of leisure and break the logic of capital through interventions promoted by the State. The construction of such critical analysis envisaged the theoretical framework presenting the leisure contradictions stimulated by capitalist social relations.
\end{abstract}

Key words: Leisure. Work. Capitalism.

O debate internacional sobre lazer está historicamente centrado no contraste entre o tempo livre e o trabalho, consagrando um campo de estudos que ocupou a atenção dos pesquisadores nas áreas de economia, psicologia, saúde/esporte e sociologia. As contribuições teóricas, se demarcado como ponto de partida o final do século XIX, evidenciam essa constatação, mas revelam que a preocupação original sobre o assunto estava associada ao direito dos trabalhadores ao bem-estar, tempo livre e trabalho justo, temas amplamente discutidos por Lafargue (1980), Kropotkin (1973 ) e Veblen (2002).

Apesar de em 2011 já ter se passado um século da morte de Paul Lafargue, ainda hoje a publicação de "Direito à Preguiça", de 1880, ganha espaço na discussão sobre o lazer, tanto pela inovadora percepção do autor, na época, como pela infindável 
problemática do "dogma desastroso do trabalho", que ainda persiste em nossas relações sociais, econômicas e políticas atuais.

Criticando a moral capitalista - como uma desprezível paródia da moral cristã, o autor, inspirado em Proudhon e Bakunin, intitula sua obra de "Direito à Preguiça" em negação ao direito ao trabalho - proclamado nas revoluções de 1848 , que Alexis de Tocquevile também ironizou, denominando-o de "direito à fome". Num contexto histórico perturbado pela espoliação do operariado, a produção intelectual da época abriu as portas para a reflexão sobre a idolatria do trabalho, seus males e consequências, tais como esgotamento das energias vitais, degeneração intelectual e outras misérias individuais e coletivas, que acompanham o capitalismo desde a sua origem.

Numa visão pendular da história, situando como central o momento da publicação da obra de Lafargue, temos a obrigação de observar o passado e o presente, ou seja, analisar os resultados que se consolidam dialeticamente no transcurso do tempo. É justamente nessa observação, que engloba as contradições da história, que poderemos compreender o processo transformador que trouxe para o âmbito do trabalho a discussão sobre tempo livre, lazer ou ócio. Sendo assim é imprescindível destacar o exemplo da sociedade burguesa europeia, que se submete às concessões do capital para a manutenção do status quo após as revoluções de 1848, abrindo mão dos direitos políticos, e da aliança de classes, em detrimento da manutenção de uma aristocracia financeira. Esta tal burguesia industrial liberal Veblen (2002) vai identificar, no cenário norteamericano de ascensão da propriedade privada, como uma classe ociosa, que nos interessa mencionar pela revelação do contraditório, com a supervalorização do trabalho para a massa operária, que é mantida alienada, paralela a sua hostilidade, que propaga uma espécie de "elogio ao ócio", exclusivo das classes proprietárias.

A obra de Thorstein Veblen, "Teoria da Classe Ociosa", publicada no final do século XIX, interpreta uma situação importante na construção deste referencial teórico, pois está focada na análise das condições do surgimento da classe ociosa e sua ostentação, desenrolando uma crítica sobre seus costumes, que incluem a demonstração ao público de que o tempo não ocupado com atividades laborais ou produtivas evidencia o status de cada individuo, ou seja, a pantomima simbólica de dominação de um lado e subordinação do outro. Dominação esta que foi permitida pelo aumento da produtividade e dos meios de subsistência suficientemente abundantes, para que uma certa parcela da humanidade esteja isenta do trabalho.

Descendente de emigrantes da Noruega nos Estados Unidos e sentindo-se ainda perdido em meio à elite industrial por ser um nostálgico da vida simples e livre, Veblen - considerado fundador da economia institucional - é descrito por Raimond 
Aron como o mais famoso dos desconhecidos sociólogos americanos 2 mas teve sua obra registrada no Books of the Century, publicado pela Oxford University Press, em 1996, como uma das obras mais importantes do Século.

$\mathrm{Na}$ busca de evidenciar a contribuição desse autor no estudo do lazer devemos destacar dois aspectos relevantes de sua caracterização da classe ociosa, quais sejam: a exclusividade do tempo livre condicionada à classe social, especificamente aquela com domínio da propriedade privada e a discriminação das tarefas laborais como dignas ou indignas, sendo as últimas julgadas sem caráter honorifico pela burguesia, pois envolvem as ocupações de vida cotidiana, em que "não entra nenhum elemento apreciável de proeza".

Como podemos observar na leitura de Veblen (2002), sobre a elite burguesa norte-americana, lazer e trabalho são considerados opostos e não se complementam já que o primeiro dirige-se a uma instituição cuja virtude é honrada por sua capacidade pecuniária, que permite uma vida de ociosidade, sem fazer nada produtivo. No topo da estrutura social essa classe ociosa impõe que, para adquirir bons modos, é necessário buscar o caráter honorifico do ócio, ou seja, o emprego não produtivo do tempo. Quem gasta tempo e energia com o trabalho não tem acesso à boa educação, pois esta exige tempo, aplicação e gastos.

Ao redigir La conquista del pan, Piotr Alexeyevich Kropotkin, ao contrário de Veblen, não se preocupa em caracterizar o lazer como privilégio de poucos abastados, mas traz uma perspectiva que indica a necessidade de ampliação deste privilégio para os trabalhadores. É lamentável que, assim como em Gramsci, a interpretação de sua obra tenha gerado abordagens equivocadas, como a ideia de que a qualidade do lazer definirá a qualidade do trabalho e o aumento da produtividade. Apropriada com outros fins, a perspectiva de Kropotkin (1973) foi utilizada para justificar que o trabalho intenso e produtivo é resultado do homem que dispõe de bem estar em proporção a seus esforços, apesar de que o autor descreve que a propriedade e/ou produção coletiva é que amplia para resultados ainda mais positivos essa tal produtividade.

Um período consagrado pelas descobertas, invenções e a busca pela paz mundial, o século XIX, em especial a última década, foi brindado com pensadores que inspiraram o comprometimento internacional com o trabalhador, compromisso esse estimulado pelo fim tardio da escravidão, pela luta por direitos humanos e a eclosão dos ideais do socialismo ocidental, mas que também sofreu influência de um dominante sistema social estabelecido pelo capital.

2 Prefácio Avez-vous lu Veblen ? escrito por Raimond Aron para a edição francesa de Teoria da Classe Ociosa 
Mesmo visto o lazer como privilégio da classe desocupada, que no entendimento de Veblen (2002) constituía a classe ociosa e, por assim ser, com permissão ao tempo livre, um novo sentido sobre o tema acompanha as diversas transformações levadas a cabo ao final do século XIX. Esse novo sentido se enraizou pela insatisfação das condições laborais do operariado, cujo mérito se deve à abordagem crítica sobre a alienação do trabalho, o direito ao tempo livre e bem-estar dos trabalhadores.

Com tantas transformações tecnológicas era de se esperar que o mundo do trabalho acompanhasse essa evolução, posto que, como argumenta Kropotkin (1973), trabalhadores já conseguem prover toda a sociedade de suas necessidades e portanto com o bem-estar necessário. Se os "não trabalhadores" ocupassem seu ócio com trabalhos úteis nossa riqueza seria ainda maior, se multiplicaria, pois a força produtiva cresce mais que a população, crescendo também o numero daqueles que vivem do trabalho alheio.

Na prática o que autor conclui é que existe uma limitação consciente e direta da produção necessária e uma duplicação da produção inútil destinada a divertir os ricos e explorar o público, inviabilizando assim o ideal do bem-estar coletivo, já que este depende que a propriedade privada se torne coletiva. Com uma produção que atenda às necessidades de todos, a sociedade estará livre para descansar e utilizar melhor suas forças, empregar melhor o tempo livre, consagrando assim o que autor nos convida à declarar como bem-estar: decidir você mesmo o que é seu bem-estar, o que é preciso para assegurá-lo e o que deve ser substituído. (KROPOTKIN, 1973)

Mas, se o século XIX foi de grandes descobertas e invenções, seria viável proporcionar a todos o acesso ao cinema, ao toca-discos, ao passeio no automóvel a gasolina, ao conhecimento das teorias psicanalítica e evolucionista, dentre outras conquistas materiais e culturais?

Kropotkin diz que o homem não é um ser que vive exclusivamente para comer, beber e dormir. Satisfeitas as necessidades básicas, materiais, o homem também tem necessidades de prazer e gozo material ou intelectual. São "necessidades de luxo mas que rompem a monotonia da existência e a torna agradável" (KROPOTKIN, 1973, p. 44, tradução nossa), tal qual expressará Marx, ao diferenciar as necessidade do estômago e da fantasia (MARX, 1996, p. 165).

Finalizando o pensamento kropotkiniano, nem todos os burgueses são ociosos e há muitos que trabalham duro, porém a diferença está em suas condições de trabaIho, bem mais adequadas e que autor considera que deveriam ser condições para todos, sem exceção.

No entanto, diante da concreta situação da sociedade, as condições igualitárias 
que deveriam atender a todos só se tornam possíveis quando associadas à produção de valores de uso sem dominação social do valor-capital, numa articulação emancipatória que substitua o domínio hegemônico por um projeto alternativo, com origem na classe trabalhadora.

Lembramos que a luta pelo direito ao lazer germinou do movimento por melhores condições de trabalho e consequentemente abriu espaço para uma série de questionamentos sobre bem-estar do trabalhador. Análogo a esta dinâmica se processou um deslocamento, onde a manipulação ideológica colocou o tempo livre a serviço do capital, como mera pausa para descanso e recomposição das forças produtivas, sustentando assim um sistema baseado na produção em massa, por meio da exploração da força de trabalho, baixos salários, redução de custos e ampliação dos lucros das indústrias. Essa trajetória de precarização é visível na análise da configuração que o capital imprime nas relações entre trabalho e liberdade, enfatizando que:

[...] com o capitalismo as atividades possíveis nos limites do tempo livre acabam se revestindo de potencialidade para que a produção de valor a mais se concretize por meio delas, o que propicia a extensão da mercantilização das coisas e das relações humanas. (MARTONI, 2014, p. 82)

O reducionismo do lazer e do tempo livre, a mera pausa entre dois momentos, inibiu a manifestação real destas categorias como fatores determinantes na satisfação das necessidades do trabalhador ou, como advertia Kropotkin, do bem estar de todos. É assim que o fenômeno do lazer só vai ser identificado pela Organização Internacional do Trabalho - OIT a partir do momento que é sinalizado como problema3, pois prejudica o sistema de produção, exigindo medidas de contenção que não responsabilizaram a elite industrial pelos próprios erros cometidos. A preocupação política era a de assegurar um tempo mínimo de não-trabalho com a finalidade de disciplinar o trabalhador e manter os níveis de produção em expansão.

O sistema de controle do tempo livre e extensão da jornada de trabalho até o máximo em termos físicos trouxe impactos de grande escala nas sociedades industriais pós-fordismo e, no âmbito do lazer, podemos apontar que para os trabalhadores gerou o sedentarismo, inibiu a criatividade, incentivou hábitos e vícios nocivos à saúde, além de diminuir a noção de tempo livre.

Da centralidade do trabalho, do capital monopolista, vamos observando aos poucos uma nova trajetória, de centralidade no lazer, que segue a mesma proposta de manutenção do capital, por meio do controle social, tal qual se evidenciava nas

3 Para aprofundamento ver a Recomendação 45, que trata da Recomendación sobre la utilización del tiempo libre, datada de 1924. Disponível em <http://www.ilo.org/dyn/normlex/es>. Acesso em fevereiro 2014. 
recomendações internacionais sobre o trabalho, que Brasil atendeu fielmente nos anos 40, com a funcionalidade do Serviço de Recreação Operária (SILVEIRA, 2015).

A centralidade no lazer, a serviço do capital, se revela como parte do jogo que também desloca a compreensão do trabalho em seu papel estruturante na sociedade e na construção da autonomia dos indivíduos.

Vejamos o exemplo recente, verbalizado em 2014, quando um dos membros da OIT, Jon Messenger ${ }^{4}$, afirmou que as pessoas são mais produtivas com uma semana menor apesar da percepção de que com mais horas de trabalho os funcionários produzem mais mercadorias ou serviços. Falando sobre a redução da semana de trabalho de cinco para quatro dias, tal especialista, Chefe do Grupo de Condições de Trabalho, reforça limites de paradigmas centrados na manutenção do sistema capitalista.

Aparentemente a redução das horas de trabalho ludibria pela ideia de incremento do tempo livre, entretanto, como vimos na visão do especialista, representa mais uma artimanha para ampliar a receita e diminuir as despesas das classes patronais, cujo interesse está sempre direcionado na ampliação dos lucros e acumulação da produção.

Contraditório por si mesmo, observamos que o lazer está vinculado ao trabalho e ao mesmo tempo precisa dele desvincular-se, sobretudo pela perspectiva de um sistema de necessidades imposto e limitado pela divisão do trabalho (HELLER, 1974), que justifica o lazer em seu caráter exclusivamente funcional.

Tal acumulação, apreendida com a leitura de Marx (2003) na Primeira Parte do Capital, sobre "Mercadoria e Dinheiro", faz parte da descrição provisória da sociedade capitalista, cuja riqueza foi concebida pela "imensa acumulação de mercadorias". Mercadorias estas que em sua origem satisfazem as nossas necessidades e cujas características determinam seu valor de troca, que nos dias atuais cada vez mais é independente das propriedades de seu valor de uso, como consequência da crescente produtividade e das mudanças na estrutura social, que de acordo com Heller (1974) promovem a conversão de necessidades de luxo ou de ostentação em necessidades necessárias ${ }^{5}$.

4 Artigo publicado originalmente em 07 de outubro de 2014 pela Rádio ONU: http://www.unmultimedia.org/ radio/portuguese/2014/10/especialista-da-oit-cita-beneficios-de-se-trabalhar-quatro-dias-por-semana/\#.VIbsSzHF_fK

5 Sobre o tema a autora diz que necessidades de luxo podem ser interpretadas como aquelas que, por costume, não pertencem à classe trabalhadora ou aquele objeto, ou consumo, que fica fora da capacidade aquisitiva da classe trabalhadora. Enquanto isso, as necessidades necessárias são aquelas surgidas historicamente e não dirigidas a mera sobrevivência (como as necessidades naturais), nas quais o elemento cultural, o moral e os costumes são decisivos e cuja satisfação é parte constitutiva da vida normal dos homens pretendentes a uma determinada sociedade. 
É assim que observamos o lazer, necessidade de luxo ou necessidade necessária, transformado em mercadoria intangível, cujo valor de troca, antes indeterminado nas relações sociais independentes da divisão do trabalho, se concretiza pela imposição da dualidade tempo livre $x$ trabalho, e pelo controle e monetarização do tempo, como fatores determinados e controlados pelo domínio do capital.

\section{O VALOR DO LAZER, NO JOGO DA ESSÊNCIA E APARÊNCIA DAS RELAÇÕES SOCIAIS CAPITALISTAS}

A história registra que a primeira transição do significado do lazer ocorre quando o homem abandona a relação integral com o meio ambiente e passa a ter domínio sobre a natureza. De acordo com McLean (2012), ao narrar o início histórico da recreação e do lazer, não existia uma distinção clara entre lazer e trabalho nas sociedades primitivas e pré-tecnológicas. Talvez por isso muitos estudos antropológicos registrem que vários artefatos descobertos foram instrumentos de trabalho ou de práticas religiosas aproveitados para fins de recreação. Arcos e flechas sem utilidade para a caça, instrumentos musicas desocupados, enfim tudo que não tinha uso em sua forma original era reutilizado para o jogo, a festa, a estética, o esporte, etc. Capturamos em Cascudo (2004, p. 580) a confirmação de nossa visão, quando o mesmo afirma que "a necessidade lúdica, o desejo de brincar, o uso de jogo é uma permanente humana".

O processo de ressignificação do lazer é dinâmico e sempre esteve associado ao conceito de liberdade, justificando que seu significado muda de acordo com o grau de como o homem se percebe e concebe a si mesmo, como um ser independente e separado, assunto que nos interessa tratar com maior profundidade em outro contexto de análise.

Na sociedade primitiva, o homem se percebia e se autodeterminava pela sua relação com a natureza, tão simbiótica que trabalho e lazer não apresentavam fronteiras, apenas se complementavam. Com a introdução a divisão do trabalho, na sociedade primitiva mais avançada, ocorre a transição do estado de natureza para o estado civilizado, que passa de uma vivência nômade para uma vivência fundada na propriedade privada, na criação e na agricultura, onde a relação com a natureza não se perde, mas começa a se distanciar, e outros domínios controlam o ser humano, um deles é o poder.

Para ilustrar o domínio do poder lembramos que da sociedade medieval até os dias atuais ainda é praticamente normal aplicar à vida cotidiana provérbios (na maioria coercitivos) que justificam condutas e regulam o pensamento popular sobre os mais diversos assuntos em sociedade. São máximas expressas em frases curtas rimadas, que 
se popularizaram como modelo de instrução eclesiástica na Baixa Idade Média (BRAGANÇA JÚNIOR, 2012) e que ainda hoje preservam de forma atemporal e imutável a sua expressão linguística, apesar das transformações na forma e estética da fraseologia.

O antigo ditado "Mente vazia, oficina do Diabo", é um exemplo dessa apropriação popular atemporal e imutável, representando um desdobramento daquilo que o filósofo e teólogo Ramon Llull registrou sobre a ociosidade no Livro dos Mil Provérbios ${ }^{6}$, escrito no ano de 1302. Em tal registro encontramos o que o pensamento llulliano julga como verdades e nos deparamos com ditados do tipo "A alma do bem que é ociosa é diligente do mal", "Devido à ociosidade estás negligente para ganhar virtudes", "Repreende a ociosidade com a consciência, a contrição e a devoção" e, para fechar de forma inusitada, "A ociosidade e a tristeza são vizinhas".

Csikszentmihalyi também exemplifica esse entendimento torpe, advertindo sobre um ditado característico da ética protestante: "O homem honesto tem suas dores e depois goza o prazer; o servente goza o prazer e, em seguida, sofre a dor" (CSIKSZENTMIHALYI, 2010, p. 315, tradução nossa).

A ociosidade encarnou essa representação medieval, de inimiga da alma, e a falta do que fazer representa uma ameaça que "incentiva o desenvolvimento de atividades não virtuosas" de ocupação do tempo livre, que privilegiam a satisfação imediata ao invés da gratificação adiada.

Como foi dito, o lazer está diretamente relacionado com a forma das relações de produção e com as concepções de liberdade e tempo vigentes em cada época. Da sociedade pré-tecnológica à sociedade industrial foi uma distante caminhada, incessantemente marcada pela ruptura, especialização, divisão e separação funcional que caracterizaram a constituição da sociedade moderna, tornando quase unânime, entre os teóricos dos anos 50, que o lazer se tratava de um fenômeno da modernidade, com objetividade e foco na organização e funcionalidade do tempo livre.

Adotando a perspectiva protestante, desde as primeiras formas de capitalismo as concepções dominantes foram de lazer como meio e não como fim em si mesmo, criando-se o mito da liberdade em relação ao tempo, sendo que o "livre" significava o "fora do trabalho", contribuindo assim para a formulação de um conceito de lazer funcional, que auxilia na resposta às necessidades de descanso e recomposição da força produtiva individual.

Com base nessa teoria, o conceito de lazer também se deturpa, pois se limita a compensação das horas trabalhadas, ganhando equivalência de tempo livre e con-

6 No livro, publicado em 1302, Ramon Llull defende o provérbio como instrumento que certifica de maneira breve a verdade de muitas coisas. São compilados em 52 capítulos organizados de forma hierárquica, como um código de virtudes, no qual são estabelecidos novos valores à sociedade. 
formando o dualismo histórico entre lazer $x$ trabalho, tal qual já predizia Aristóteles ao enunciar que trabalhamos para ter ócio e fazemos a guerra para ter paz. 0 detaIhe deste enunciado é que tal benefício do ócio é perseguido por toda gente porém, em detrimento da classe forçada a trabalhar, usufruem em toda sua plenitude apenas o grupo que Thorsten Veblen designará futuramente de "classe ociosa".

Na sociedade capitalista, que reúne em suas mãos tanto os meios de produção como a força de trabalho, a relação do homem com os seus processos de trabalho e de não-trabalho foi afetada de tal forma que, ao mesmo tempo que sacia as necessidades também cria uma nova série delas, dentre as quais podemos evidenciar o surgimento do "valor de troca do lazer", baseado no embate entre a necessidade alienada, produzida economicamente e a necessidade não alienada, que caracteriza o "valor de uso do lazer", como uma categoria positiva, que se aproxima daquilo que Heller (1974, p. 80) identifica em Marx como a necessidade do "homem socializado".

No interior de um sistema de produção capitalista, com princípios liberais, o fenômeno do lazer foi cada vez mais desviado da sua origem de gratuidade e liberdade que possibilitaria este "homem socializado", incorporando um dualismo existencial que impôs uma relação duradoura com o universo do trabalho, sui generis ao desenvolvimento das sociedades primitivas onde a diversão, os jogos, as festas, as brincadeiras e outras atividades espontâneas faziam parte do dia-a-dia, entremeando instantes de trabalho e práticas sociais, já que o trabalho não era uma necessidade imposta ou obrigatória socialmente.

Perigosamente se atribui que nos dias atuais é possível recuperar essa integração dos momentos de tempo livre com trabalho, a partir do discurso de que a sociedade moderna aplica valores subjetivos associados aos mesmos prazeres do lazer em atividades laborais, que Ihe são gratificantes. (DE GRAZIA, 1966; DUMAZEDIER, 1999) Ou, como expõe Adorno \& Horkheimer (1981), associa o entretenimento como uma extensão do trabalho, na reprodução dos processos tecnológicos ou imitando produtos que serviriam ao próprio trabaIho no capitalismo tardio. De qualquer forma, fica evidente que, na essência, o intervalo, denominado tempo livre, reproduz ideologias e condições de dominação sob a forma de entretenimento coletivo e alienado, figurando um "lazer aparente" muitas vezes promovido pelo próprio Estado.

Cabe ressaltar que, como direito social, o lazer é uma dessas prestações sociais que o Estado deveria atender, e que é reconhecido, nos protocolos internacionais vigentes e na Declaração dos Direitos Humanos, como um bem social indispensável, cujo avanço abre as potencialidades dos sujeitos em busca de uma vida com qualidade.

Sabemos, em contrapartida, que a influência do discurso ideológico dominante do 
Estado interfere no senso comum da sociedade, resultando na negação da necessidade do lazer e incorporando um conceito depreciado e pejorativo para a classeque-vive-do-trabalho (ANTUNES, 2009), que o qualifica apenas para a "classe ociosa vebleniana". Nos países que ainda não alcançaram uma cobertura de bem-estar social satisfatória para sua população, em que o Brasil se mostra como exemplo, a realidade cotidiana se expressa pela busca individual dos direitos mínimos de sobrevivência e por serviços e infraestrutura básica que atendam a maioria de uma população carente, com poucas expectativas para o lazer.

Ainda assim, diante de um quadro que parece desfavorável e marcado pelo valor aparente do lazer, consideramos relevante o estudo deste tema, pois é na qualidade do uso do tempo livre que são fundadas as bases do desenvolvimento humano, perpassando Soma-se ainda o fato de que mesmo nas condições mais adversas sempre existe um espaço para a manifestação da brincadeira, da festa, do jogo e de tantas outras manifestações de lazer, que fazem parte da "casa e da rua" da população brasileira, até o momento em que não estejam subjugadas ao valor de troca e à manutenção do capital desenfreado que transforma o tempo de vida, designado por Antunes (2009), em tempo controlado pelo capital.

A partir deste olhar concreto, nos propomos a analisar a essência do lazer que se revela como um exemplo de submissão das relações de hegemonia poderosas e duradouras, que expressam determinações econômicas, políticas, sociais e culturais produzidas pelo modo de produção capitalista - que determina a quantidade e a qualidade do tempo livre do trabalhador.

Podemos observar um circulo vicioso do lazer que se adapta às mudanças da ordem socioeconômica estabelecida e convive em função dos fatores ideológicos que a mantem, favorecendo a criação incessante de novos bens de consumo para o tempo livre, que não satisfazem as necessidades de desenvolvimento pessoal dos indivíduos, mas criam outras de caráter puramente efêmero, cujos produtos veiculados pela mídia, pelo Estado e pelas classes patronais encobrem a real essência que lhe precede. Citamos como exemplo a atuação do Governo Federal diante da estruturação de um programa de acesso a cultura para o trabalhador, que movimenta a indústria cultural e do entretenimento, privilegiando em primeira escala grandes estruturas de cinemas, livrarias e negócios lucrativos de padronização cultural e artística.

Pellegrin $(2006$, p. 108) caracteriza o santuário, onde se estabelecem as trocas comerciais desta indústria cultural de lazer aparente, como "um campo vasto de investimento e exploração de negócios lucrativos, uma vez que é possível trabalhar a partir dessa demanda de 'felicidade' pelo consumo" sob a exploração de uma oferta diversificada de viagens, espetáculos, esportes, compras, tecnologia, etc. 
É uma realidade que expressa o abandono da economia produtivista por uma economia consumista que Bauman (2001) vai identificar como a passagem da modernidade sólida para a modernidade líquida, caracterizando a mudança de paradigmas, com o abandono da centralidade no trabalho em direção à valorização do consumo, que caracteriza a modernidade privada, regulada e compulsiva.

A busca daquilo que socialmente é moldado pela sociedade e tem prestigio perante o outro também se insere nas contradições do lazer, que de uma forma geral atende várias expectativas, sejam elas significativas ou simplesmente espetáculos que concretizam a alienação. Refletir sobre essas contradições faz parte do desafio de avaliar o valor do lazer no jogo da essência e aparência das relações sociais capitalistas, bem como de discutir a adesão ou emancipação do lazer diante desse universo material, simbólico e instantâneo da denominada "modernidade líquida".

Diante do jogo das relações sociais capitalistas a superação do "valor utilitário" do lazer por seu "valor de uso" exige uma mudança qualitativa difícil, que equipare os valores hedonistas (bem-estar, felicidade, prazer e diversão) com os atributos de uma experiência pessoal consciente, capaz de garantir benefícios individuais e coletivos, os quais caracterizariam uma resposta à demanda coletiva das classes sem disposição para o consumo, mas abertas ao que Cabeza (2000) define como um modo de ser e perceber, um estado mental ou um âmbito da experiência humana.

No entanto, podemos concluir que em termos de perspectivas sobre as políticas de lazer, existem duas vertentes fundamentais: a perspectiva do lazer como direito e necessidade atendida exclusivamente pelo Estado Elitista e outra, denominada de Pluralista, onde as políticas devem ter a participação da iniciativa privada e não-governamental, o que pressupõe múltiplas formas de autoridade e um governo aberto e acessível. Essa última perspectiva vem cristalizando uma tendência de questionamento sobre a exclusividade do público nas políticas de lazer, ideia que se sustenta pela crítica de autores como lan P. Henry (1993) e Thomas Burton (1982). O último introduz em sua análise quatro setores diferentes como policy-makers, ou desenhistas dessas políticas, quais sejam: governamental, privado, voluntario e comercial.

A questão intrigante é que tal perspectiva se instalou como forma hibrida de neo-institucionalismo, contrária a abordagem centralizada no Estado elitista, de matriz weberiana, e fundada numa matriz pluralista, onde o Estado tem a função neutra de agregar preferências e integrar a sociedade em valores consensuais.

Ambas concepções de Estado tem seus perigos, pois, enquanto uma age em favor da elite burocrática, outro atende à mesma elite, numa ação vinculada à servidão aos valores centrais e consensuais, que no final das contas são definidos pela própria elite. 
O que nos alerta diante desta realidade é que as condições de vida do cidadão brasileiro vêm se transformando de forma acelerada, influenciadas, sob a tutela do Estado, pelo metabolismo socioeconômico (MÉSZARÓS, 2002), afetando a formas de mobilidade, de moradia, de trabalho, de relação com o meio ambiente e de uso do tempo livre, entre outros aspectos. Tais mudanças são acompanhadas de forma precária e anacrônica, por meio de pesquisas, estatísticas e estudos sem caráter transformador, já que atendem ao padrão de manutenção das verdades aparentes, sem desvelar que propostas, como a do programa de acesso à cultura citado, tenham sua intenção atrelada à formação social capitalista.

Como definiu De Grazia, transformar tempo livre em lazer é uma tarefa difícil, e profetizando aquilo que hoje se materializa como realidade nas estatísticas, alerta para o seguinte:

A forma não crítica e imóvel que se emprega o tempo livre - em casa, nas tardes, em atividades que não requerem nem pensamento nem esforço, principalmente como expectador em uma poltrona - parece se relacionar com o ritmo e a concentração de trabalho [...]. (DE GRAZIA, 1966, p. 292, tradução nossa)

De fato, a pesquisa piloto do Instituto Brasileiro de Geografia e Estatística - IBGE, durante a PNAD Continua em 2009, indica que o padrão de uso do tempo7 dos brasileiros que vivem no espaço urbano de cinco unidades federativas, se caracteriza, no aspecto do lazer, pela concentração de um maior número de horas na dedicação de atividades relacionadas ao "uso dos meios de comunicação de massa", que de acordo com a CONCLA8, se referem às atividades de leitura, assistir televisão e vídeo, escutar rádio e áudio, uso do computador e visita a biblioteca.

Outras atividades que caracterizam o uso do tempo livre dos brasileiros foram as relacionadas aos "eventos culturais, hobbies e esportes", que apesar da relevância do tempo ocupado não superam os "afazeres domésticos", principalmente se consideramos o tempo disponível da mulher, que se dedica 1 hora e 31 minutos a mais que os homens. A "socialização" também ocupa um tempo significativo dos brasileiros, que registram um total diário de 2 horas e 21 minutos para conversar, participar em eventos sociais, fazendo ou recebendo visita.

Inevitavelmente, percebemos que o tempo dedicado ao trabalho consome, e tende a ampliar, a maior parte do tempo do brasileiro que realiza essa atividade,

7 De acordo com o IBGE o levantamento piloto sobre o uso do tempo deveria servir para formatar a pesquisas futuras do órgão sobre o tema mas até o momento, desde 2009, não se realizaram publicações de avanços, deixando uma iniciativa promissora para as políticas de lazer, sem continuidade e sincronia com a realidade.

8 A CONCLA disponibiliza as classificações estatísticas nacionais usadas no sistema estatístico e nos cadastros administrativos do Brasil e as classificações internacionais. 
restando pouca oportunidade de tempo livre ${ }^{9}$ e refletindo aquilo já evidente no cenário da concorrência global, onde países da América Latina e Ásia, com salários mais baixos, representam a principal força do competitivo mercado de trabalho internacional, que amplia e generaliza formas de trabalho parcial e precário.

Não apenas o tempo de trabalho é consumido pelo sistema sociometabólico totalitário, mas o tempo de não-trabalho também. O risco dessa apropriação do tempo-livre pelo capital é a transformação daqueles instantes que seriam do "reino da liberdade", indicado por Marx (2003), em tempo de alienação, fetichismo e estranhamento, ou seja, indicações que expressam o caráter capitalista da sociedade contemporânea e sua lógica destrutiva (ANTUNES, 2002).

Consequente da redução da jornada de trabalho ou quando este deixa de ser determinado por necessidade ou utilidade, o "reino da liberdade" constitui um ideal imprescindível para uma experiência valiosa de lazer, entretanto, pressionado pelo fetichismo da mercadoria e pelo controle do capital, tal experiência se torna alienante, resultando na preferência de atividades sem autonomia, motivação, criatividade e satisfação.

As pesquisas sobre o uso do tempo apontam esse caminho, já que a preferência dos brasileiros é por um lazer passivo, dedicado a utilização dos meios de comunicação, como a TV e a internet. A população não faz o aproveitamento do espaço público e do espaço de convívio coletivo no seu tempo livre de obrigações, seja pela atratividade da casa, como espaço de lazer ou pela desvalorização da função urbana do lazer por parte dos gestores públicos.

O fenômeno descrito vai ao encontro do que Santos (2005) denomina de urbanização corporativa, que caracteriza o panorama de ocupação e organização das cidades a partir do Brasil moderno, pós-1964.

Incentivada pela expansão capitalista patrocinada pelos recursos públicos, a urbanização corporativa favoreceu o interesse das grandes empresas, com modelos preestabelecidos de categorias espaciais, dentre as quais aquelas que atendem aos objetivos da especulação e dos interesses do capitalismo monopolista.

Vazios urbanos, circulação rodoviária sobrecarregada, proliferação de espaços habitacionais periféricos, carência de infraestrutura, marketing urbano e especulação imobiliária são apenas alguns dos fatores que contribuem para a urbanização corporativa e demonstram a problemática do crescimento urbano nas cidades brasi-

9 Situação que é bem diferente quando comparamos com os 18 (dezoito) países que compõem a Organização para a Cooperação e Desenvolvimento Econômico - OCDE, sem esquecer as diferenças internas que caracterizam esse grupo de países, tendo em vista que as horas dedicadas ao lazer por eles superam à média das horas de trabalho, favorecendo a prática de atividades de livre escolha, que compõem o leque de opções do lazer. 
leiras. Acrescentando ainda a seletividade dos espaços podemos perceber que não houve nenhum esforço no sentido da socialização dos lugares, ou como diria Santos (2005), em favor da "cidade social".

A cidade econômica prevaleceu até meados dos anos 90 , quando as consequências do processo corporativo se evidenciaram na forma de um crescimento acelerado das áreas urbanas e consequentemente a metropolização intensa, principalmente nas regiões sul e sudeste.

A realidade ainda é mais agravante quando constatamos que foi a população de mais baixa renda a maior prejudicada por essa dinâmica urbana, consequência que se reflete na percepção dos equipamentos culturais, cada vem mais distantes quando menor a classe de renda familiar ${ }^{10}$.

A lógica do capital está presente em quase todas as instâncias de nossas vidas e no que tange ao lazer a realidade não seria diferente, pois a "indústria do entretenimento" investe crescentemente numa concepção de lazer baseada no efêmero, que Silveira (2015) vai destacar na concepção das "políticas de instante", como aquelas cujo aprofundamento das ações é fluído e inconsistente, combinado com uma temporalidade instantânea e descontinua, concebidas sob a pressão de paradigmas que legitimam o discurso ideológico dominante e atendem de forma aparente a problemática do direito ao lazer.

A centralidade do lazer, que muitos autores profetizam deslocar o trabalho do núcleo de nossas vidas, não desloca consigo a subordinação das relações sociais ao capitalismo tardio, pelo contrário, está a serviço dele, e pasmem, tem o Estado como principal protagonista.

\section{CONSIDERAÇÕES FINAIS}

Se no jogo da aparência, tanto o Capital como o Estado ( por meio de seus aparelhos ideológicos e coercitivos) representam o lazer como direito, tempo livre e conquista dos trabalhadores, na essência encontramos os reais fundamentos, que revelam um conceito de lazer utilitário, instrumental e sem sentido, que controla e persuade o trabalhador, enlatando experiências postas ao consumo por uma "sociedade do espetáculo", de Debord (1994) ou da "euforia perpétua", como designou o filósofo francês Pascal Bruckner (2002).

10 Sobre este tema, ver a pesquisa do INSTITUTO DE PESQUISA ECONÔMICA APLICADA - IPEA. Sistema de Indicadores de Percepção Social/SIPS. Cultura. 1 ed. [S.I.]: IPEA, 2010 e Sistema de Indicadores de Percepção Social/SIPS. Trabalho e Tempo Livre. 2 ed. [S.I.]: IPEA, 2012. 
O lazer se engendra na dinâmica de produção capitalista, como um fenômeno que se assume como experiência e ao mesmo tempo como produto de consumo, no qual não existe materialidade, já que é intangível e se concretiza de forma diferente para cada individuo. Assim, se o sistema capitalista de produção cria os objetos necessários para o desfrute do lazer, a distribuição reparte de acordo com as leis sociais e a troca reparte novamente de acordo com as necessidades individuais, ou seja, uma tem origem na sociedade e outra no individuo, tal qual descreve Marx (2003).

Ao se configurar tal abordagem, lembremos que as mercadorias devem satisfazer as necessidades humanas, sejam necessidades do estômago ou da fantasia (Marx, 2003; Heller, 1974) e que o valor do lazer se encontra expresso justamente nesta segunda categoria, que sugestivamente compreende o reino da liberdade.

Socialmente produzidas, as formas de manifestação e desfrute do lazer estão repletas de valor de uso, porém só na sociedade capitalista se reverteram em valor de troca, da mesma forma que se configuram as necessidades criadas a partir da divisão do trabalho, que segundo Heller (1974, p. 23), determina e limita sua estrutura.

Seja pelo caráter descrito por Cascudo (2004) como permanente humana desejada pelo lúdico e pela liberdade ou em função da satisfação de necessidades provocadas pela divisão do trabalho, o que se atenta é que o lazer ampliou o seu espaço de troca e se adaptou facilmente às relações simbólicas da modernidade, encontrando outra forma de circulação ainda mais incansável, representada pelo metabolismo social do capital, que de acordo com Mészáros (2002) tem seu núcleo formado pelo tripé capital, trabalho e Estado.

Tais relações simbólicas entram em harmonia com as expressões da aparência e da essência do lazer. Estas apresentaram diversas configurações ao longo da história, como podemos observar no decorrer deste texto, que evidenciou contradições que se revelam nas formas de resistência ou de alienação da sociedade.

Levando em conta que o capital condiciona uma violenta imposição no comportamento dos indivíduos, entendemos que o vínculo com o trabalho dá conta de fornecer uma importante contribuição para a compreensão aprofundada das relações sociais, inclusive dos aspectos da essência e aparência do lazer na sociedade atual, cuja totalidade concreta é expressa por representação e conceito das coisas em si (KOSIK, 2010), ou seja por aparência e essência, que são mutáveis em função da forma de produção material da vida social.

Por isso dizemos que a busca de conteúdos originais que revelam o lazer como necessidade humana e direito social conquistado, e também perdido, pela luta dos 
trabalhadores, configura uma experiência e um conceito de lazer que, adotando o conceito de flow, do psicólogo Csikszentmihalyi (2010), é designada como experiência valiosa11 "ou que convertem-se no maduro e completo ócio humanista, de Cabeza (2000). Esta perspectiva se traduz nas seguintes características do lazer:

- Experiência pessoal não obrigatória, livre e permitida ou que permite, seja o descanso, o desfrute, o desenvolvimento humano enfim, tudo que não for guiado por metas ou utilidade.

- Necessidade humana que tem fim em si mesmo e tem relação com o estado físico, emocional, intelectual e espiritual da pessoa.

- Fenômeno individual e social, de autoafirmação e identificação do indivíduo e seu coletivo.

- Satisfação que se garante pela motivação e exercício da liberdade percebida, em contraposição ao exercício da liberdade determinada. Supõe a liberdade "para" ao invés da liberdade "de".

- Experiência de caráter processual que faz parte de nossas vidas por meio de um diálogo temporal entre passado, presente e futuro, conformando uma vivência completa para além de atividades objetivamente consideradas, como o mero passatempo ou a recreação compensatória.

Logicamente o alcance desse novo lazer só será possível com a desintegração da subordinação do trabalho ao capital, fato que segundo Mészarós (2002) já podemos vislumbrar como possível mediante vários indicadores, inclusive pela questionamento dos intelectuais à autoridade do capital, devido ao crescente desemprego e à clivagem entre a formação e as oportunidades de emprego. Outro aspecto que é levado em conta pelo autor como indicador é a crise do montante crescente que ele denomina de "tempo supérfluo", para designar esse lazer cuja essência se manifesta na manutenção de um amplo segmento da população em "estado de apatia, divorciado de suas próprias capacidades intelectuais".

Observando estes sinais é possível falar em outro tipo de lazer, a partir da emancipação do trabalho, não em termos da "sociedade do lazer", livre do trabalho, mas como nova forma de trabalho, que Antunes (2002, p. 132) diz realizar, em sua integralidade, a omnilateralidade humana, o livre desenvolvimento de individualidades e a emancipação do ser social.

11 Essa relação é discutida por Monteagudo (2004) ao se referir nos repertórios de lazer. 


\section{REFERÊNCIAS BIBLIOGRÁFICAS}

ADORNO, T. W. , HORKHEIMER, M. A indústria cultural: o esclarecimento como mistificação das massas. In: . A Dialética do Esclarecimento. Rio de Janeiro/RJ: Zahar, 1981, p. 113-156.

AMIGO, Jaime Cuenca. Tiempo ejemplar: El ocio y los mundos vivenciales. In: CABEZA, Manuel Cuenca; GUTIÉRREZ, Eduardo Aguilar. El tiempo del ocio: Transformaciones y riesgos en la sociedad apressurada. Bilbao/Espanha: Universidad de Deusto, 2009 , p. $57-73$.

ANTUNES, Ricardo. Adeus ao Trabalho? Ensaio sobre as metamorfoses e a centralidade do mundo do trabalho. Campinas/SP: Cortez Editora, 2002.

. Os Sentidos do Trabalho: Ensaio sobre a afirmação e a negação do trabalho. São Paulo/SP: Boitempo, 2009.

BAUMAN, Zygmunt. Modernidade Liquida. Rio de janeiro/RJ: Jorge Zahar Editores, 2001.

BRAGANÇA JÚNIOR, Álvaro Alfredo. A fraseologia medieval latina. Originalmente apresentada como Dissertação de Mestrado, Universidade Federal do Espírito Santo, Vitória/ES, 2012.

BRUCKNER, Paschal. La euforia perpetua: sobre el deber de ser feliz. Barcelona/ Espanha: Tusquets Editores S.A, 2002.

CABEZA, Manuel Cuenca. Ocio humanista: dimensiones y manifestaciones actuales del ócio. Bilbao/Espanha: Universidad de Deusto, 2000.

. Valores que dimanan del ocio humanista. In: ORTUZAR, Aurora Madariaga y AMIGO, Jaime Cuenca (Org.). Los valores del ocio: cambio, choque e innovación. Documentos de Estudios de Ócio. Bilbao/Espanha: Universidad de Deusto, n. 43, 2011. p. 17-48.

CASCUDO, Luis da Câmara. Civilização e Cultura. São Paulo/SP: Global Editora, 2004. CSIKSZENTMIHALYI, Mihaly. Leisure and Socialization. In: ROJEK, C. (Org.). Leisure studies. Los Angeles/EUA: Sage, 2010. 315-323.

DE GRAZIA, Sebastian. Tiempo, trabajo y ócio. Madrid/Espanha: Editorial Tecnos AS, 1966.

HELLER, Ágnes. Teoria de las necessidades em Marx. Barcelona/Espanha: Ediciones Peninsula, 1974.

KOSIK, Karel. Dialética do concreto. Rio de Janeiro: Paz e Terra, 2010. 
KROPOTKIN, Piotr Alexeyevich. La conquista del pan. Bilbao/Espanha: Zero, 1973. LAFARGUE, Paul. O Direito à Preguiça. São Paulo/SP: Kairós Livraria e Editora, 1980. MARTONI, Rodrigo Meira. Por uma ontologia do espaço turístico: contribuições para uma consciência do real e do possível. Originalmente apresentada como Tese de Doutorado, Programa de Pós-graduação em Geografia, Universidade Federal do Paraná, Curitiba/PR, 2014.

MARX, Karl. O Capital: Crítica da Economia Política. Rio de Janeiro/RJ: Civilização Brasileira, 2003. (volume 3)

. O Capital: Crítica da Economia Política. Coleção Os Economistas, São Paulo/ SP: Abril Cultural, 1996. (Tomo 1)

McLEAN, Daniel. Kraus'Recreation and leisure in modern society. EUA: Jones \& Bartlett learning, 2012.

MÉSZÁROS, István. Para além do capital. São Paulo/SP: Boitempo Editorial, 2002.

PELLEGRIN, Ana de. Lazer, Corpo e Sociedade: Articulações críticas e resistências política. In: PADILHA, Valquiria. (Org.). Dialética do Lazer. São Paulo/SP: Cortez, 2006. p. 104-125.

SAN SALVADOR DEL VALLE, Roberto. Políticas de ocio. Bilbao/Espanha: Universidade de Deusto, 2000.

SANTOS, Milton. A urbanizaçao brasileira. São Paulo/SP: Edusp, 2005.

SILVEIRA, Shaiane Vargas. Da Política de Instante à Política para o Instante. Uma crítica de políticas públicas de lazer no Brasil. Originalmente apresentada como Tese de Doutorado, Programa de Pós-graduação em Políticas Públicas, Universidade Federal do Maranhão, São Luis/MA, 2015.

VEBLEN, Thorstein. Teoria de La Clase Ociosa. Madrid/Espanha: FCE, 2002.

WORLD LEISURE ORGANIZATION. International Charter for Leisure Education. Cedar Fall/EUA: WLO, 1993 